JAIME ORTEGO ${ }^{\mathrm{a}}$ - M. PILAR MIER DURANTE ${ }^{\mathrm{b}}$ - JUAN M. NIETO NAFRÍA ${ }^{\mathrm{c}}$

\title{
APHIS CORDUBENSIS SP. N. (HEMIPTERA APHIDIDAE) LIVING ON ABUTILON MEGAPOTAMICUM (MALVACEAE) FROM CORDOBA PROVINCE (ARGENTINA)
}

\author{
${ }^{a}$ Avenida Carlinda 18, 29010 Málaga (Spain) [previously: Estación Experimental Agropecuaria Mendoza \\ (INTA), Luján de Cuyo (Mendoza, Argentina)]; ortegojaime@yahoo.com.ar; ORCID ID: 0000-0001-9738-7085 \\ b Departamento de Biodiversidad y Gestión Ambiental, Universidad de León, 24071 León (Spain); \\ mpmied@unileon.es; ORCID ID: 0000-0001-7834-1778 \\ c Departamento de Biodiversidad y Gestión Ambiental; Universidad de León, 24071 León (Spain); \\ jmnien@unileon.es; ORCID ID: 0000-0001-6714-2415
}

Ortego J., Mier Durante M.P., Nieto Nafría J.M. - Aphis cordubensis sp. n. (Hemiptera Aphididae) living on Abutilon megapotamicum (Malvaceae) from Cordoba province (Argentina)

Corresponding Author: Juan M. Nieto Nafría, jmnien@unileon.es

Aphis cordubensis sp. n. (Hemiptera: Aphididae) is described from apterous and alate viviparous females, oviparous females and males collected in Villa Carlos Paz (Córdoba, Argentina) on Abutilon megapotamicum. A summarized identification key for apterous viviparae of Aphis species recorded worldwide on Malvaceae is presented. The diagnostic features allowing to differentiate the new species from the Aphis species known in South America are presented. The new species should be able to live in Argentina, Brazil and Uruguay on wild and cultivated plants of Abutilon and perhaps on other genera of Malvaceae. The species is potentially invasive and trade and cultivation in gardens and plant nurseries of Abutilon and close genera must be monitored.

KEY Words: Aphis, Aphididae, new species, Argentina, Abutilon, Malvaceae

\section{INTRODUCTION}

The first author collected a sample of aphidsapterous and alate viviparous females, oviparous females, and males - on some cultivated specimens of Abutilon megapotamicum (A.Spreng.) A.St.-Hil. \& Naudin (Malvaceae) in the garden of the hotel where the XIII Latin American Congress of Phytopathology was held, in Villa Carlos Paz (Córdoba, Argentina) in April 2005. A new species of Aphis Linnaeus, 1758 (Hemiptera, Aphididae) is described below from these specimens.

\section{MATERIALS AND METHODS}

Standard protocols for collection, ethanol preservation, slide preparation, and morphometric study have been employed. Studied specimens are listed in the "Types" section. Identification keys and comments by LÓPEZ CIRUElOS et al. (2017), NIETO NAFRÍA et al. (2019) BLACKMAN and EASTOP (2021) and papers published after 2017 describing new species of Aphis from Argentine or Chilean specimens, were used for the initial identification of the specimens. Microphotographs were taken using an iPhone 7 through an eyepiece adapted to an Olympus CX41 microscope and subsequently treated with Corel Photo-Paint 2018 and Microsoft Publisher 2010.

\section{RESULTS AND DISCUSSION Aphis (Aphis) cordubensis sp. $\mathrm{n}$.}

(Figs. I \& II; Table 1)

TYPES

Holotype, apterous viviparous female (ARG-1713apt.4, mounted alone): ARGENTINA, Córdoba province, Punilla Department, Villa Carlos Paz (31 ${ }^{\circ} 24^{\prime} 01^{\prime \prime}$ S, $64^{\circ}$ $28^{\prime} 48^{\prime \prime} \mathrm{W}, 650 \mathrm{~m}$ ), on Abutilon megapotamicum, University of Leon collection.

Paratypes: 16 apterous viviparous females, 57 alate viviparous females, 15 oviparous females and 5 males, same data than the holotype; University of León, Natural History Museum, London and J. Ortego collections. DESCRIPTION

Apterous viviparae (Figs. I, 1-4). From 17 specimens (10 measured). When alive pear-shaped, dark green to greenish black and slightly waxy white powdered. 1.375-1.725 mm long. When mounted, light brown or beige because thorax and abdomen are widely membranous, with head, antennnal segments I, II, V in part and VI, distal part of rostrum, hind femora in part and dorsal sclerites pale brown to brown, clypeus, mandibular and maxillary lames, distal part of rostrum, coxae, distal portion of tibiae, tarsi, genital and anal plates, and cauda brown to dark brown, and siphunculi dark to very dark brown. Setae very long, fine and pointed. Head without reticulation, with few or very few scattered rectilinear ridges. Frons slightly convex or somewhat wavy. Antennae six-segmented or fivesegmented by fusion of segments III and IV, always slight- 

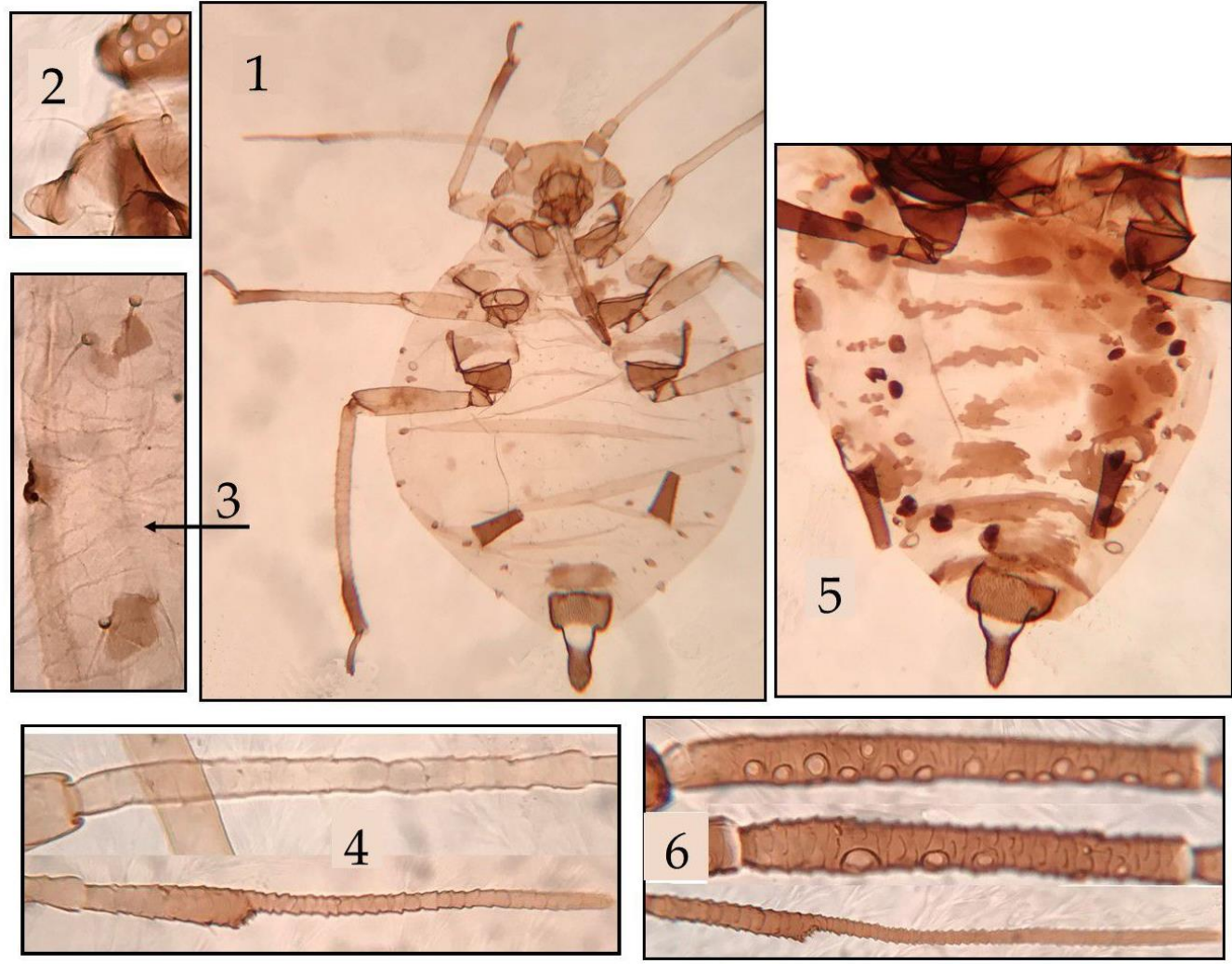

Fig. I - Aphis cordubensis sp. n. - 1-4, apterous viviparae (ARG-1713-apt.4, holoype); 5-6, alate viviparae (ARG-1713al.1). 1, complete view $-1.725 \mathrm{~mm}-;$ 2, prothoracic marginal tubercle; 3, marginal area of intermediate abdominal segments; 4, antennal segments II (part), III $-0.20 \mathrm{~mm}-$, IV $-0.13 \mathrm{~mm}-$, V (part) and VI $-0.11+0.23 \mathrm{~mm}-; 5$, abdomen body length, $2.150 \mathrm{~mm}-;$, antennal segments III $-0.36 \mathrm{~mm}-$, IV $-0.24 \mathrm{~mm}-$ and VI $-0.15+0.33 \mathrm{~mm}-$.
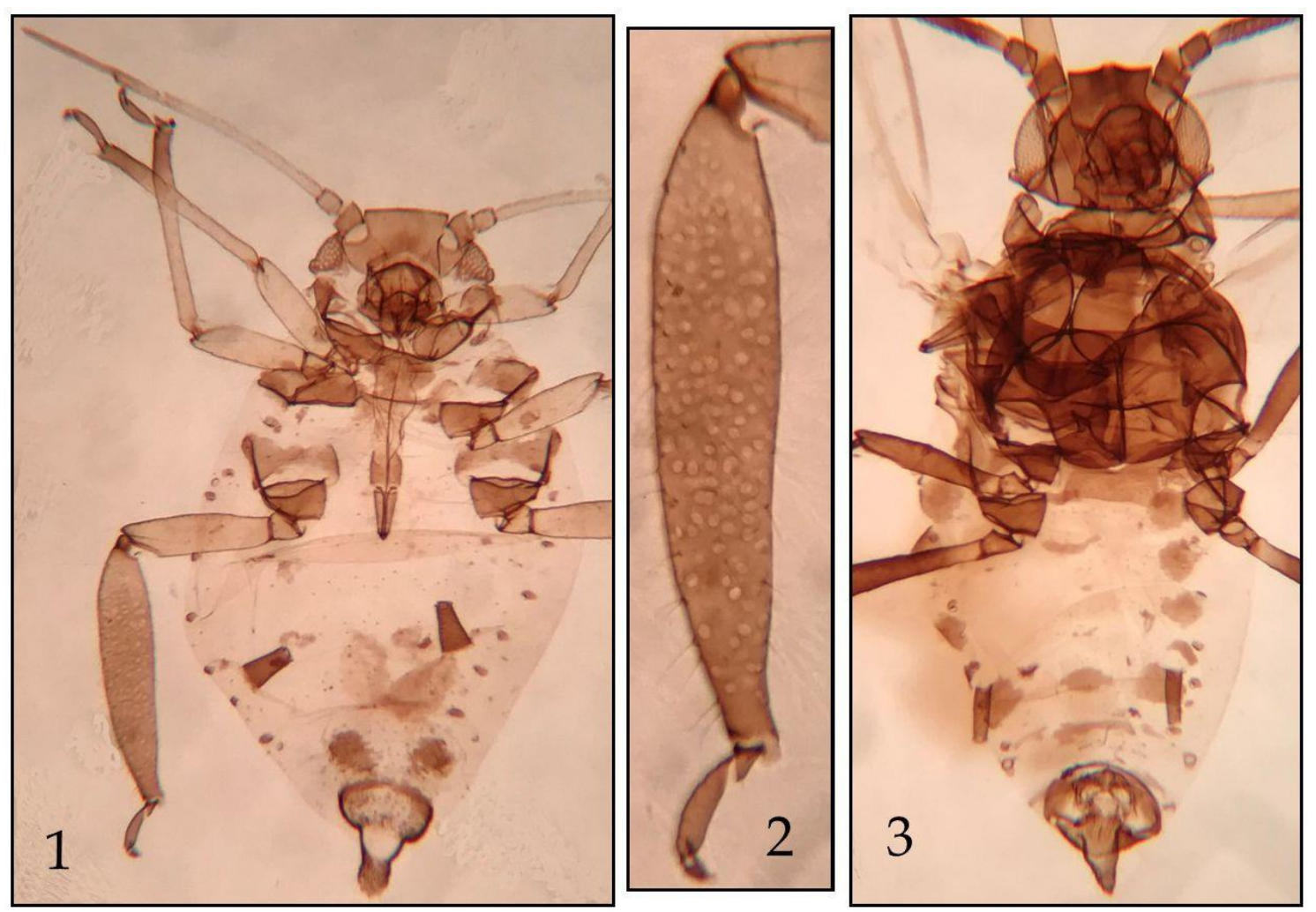

Fig. II - Aphis cordubensis sp. n. - 1-2, oviparous female (ARG-1713-ov.1); 3, male (ARG-1713-m.5). 1, complete view $-1.575 \mathrm{~mm}-; 2$, hind tibia $-0.55 \mathrm{~mm}-; 3$, complete view $-1.738 \mathrm{~mm}-$ 
ly longer than half body. Antennal segments I and II with scattered ridges. Antennal segments III or III+IV ventrally smooth and dorsally few ornamented, and with 4-7 setae; antennal segment IV if separated, pale and little ornamented. Antennal segments V and VI imbricate. Processus terminalis of antennal segment VI markedly long for what is usual in the South American species of the genus. Rostrum reaching or slightly passing hind coxae. Ultimate rostral segment thick, with straight edges, and as is typical in the subgenus with 2 accessory setae. Prothoracic marginal tubercles tall, less voluminous than triommatidia and bigger than those on abdominal segments 1 and 7. Abdominal segments 2 to 4 sometimes with marginal tubercles, 1 or 2 on each side and no more than 2 in total. Abdominal segments 5 and 6 without marginal tubercles. Dorsum of thorax tenuously reticulated, with a somewhat more noticeable intensity on the sclerites: spinal and marginal on prothorax and mesothorax and pleural on metathorax. Tarsal formula 3.3.2. Abdominal segments 1 to 7 without segmental sclerites and very little marked reticulation. Abdominal segment 8 with a transverse band or paired sclerites with scattered spinules, and carrying 2 or 4 setae. Intersegmental sclerites small and dark. Siphunculi tapering, imbricated and with a very small flange. Genital plate with 2-4 discal and 6-11 posterior setae. Cauda broad and long finger-shaped, and carrying 8-12 setae. Metric features in Table 1.

Alate viviparae (Figs I, 5-6). From 57 specimens (21 measured). When alive greenish black and brown and slightly waxy white powdered. 1.613-2.600 mm long (usually $1.65-2.43 \mathrm{~mm}$ ). When mounted with head (including clypeus and lames), antennae, thorax, coxae, middle and hind femora, apical portion of tibiae, tarsi, and siphunculi dark to very dark brown, rostrum, front femora, genital and anal plates and cauda brown to dark brown, and dorso-abdominal sclerites pale brown to brown contrasting on membranous abdominal dorsum. Frons straight, head and antennal segments I and II with abundant and marked roughness. Antennal segments IIIVI imbricated. Antennal III with (4)7-12(15) setae and 8-17(24) [19-34(41) on both antennae] secondary sensoria big and scattered on three quarter of ventral face. Antennal segment IV with 1-8 [5-14 on both antennae] secondary sensoria, also big. Antennal segment $\mathrm{V}$ with 0-3 [0-4 on both antennae] secondary sensoria smaller than the others. Intersegmental sclerites larger than those of aptera. Abdominal segments 1-6 with spinal or pleurospinal bands and marginal sclerites or patches, sometimes reduced in quantity or surface. Abdominal segments 2-4 with $0-3 \quad[0-4$ on both sides $]$ marginal tubercles. Segments 7 and 8 with transverse band, usually broad and arc-shaped, with scattered spinules. Genital plate with 10-19 posterior setae. Cauda with 12-20 setae. Omitted characteristics like those of the apterae. Metric features in Table 1.

Oviparae (Figs. II, 1-2). From 39 specimens (15 measured). When alive greenish black and slightly waxy white powdered and long pear-shaped, because the last abdominal segments are long, as it is common in many species of Aphis, and with tibia of hind legs very swollen.
1.363-1.625 mm long. Sclerotization and pigmentation in general like those in apterous viviparae, with very swollen hind tibiae uniformly brown, middle third of both genital and anal plates pale, and cauda posterolaterally something depigmented. Frons straight. Antennal segment III with 4-12 setae. Marginal tubercles on the intermediate abdominal segments usually absent, and never more than one in total on both sides. Abdominal segment 8 with $4-15$ setae. Genital plate with 35-50 setae. Cauda with 10-18 setae. Omitted characteristics like those of the apterous viviparae. Metric features in Table 1.

Males (Fig. II, 3). From 6 specimens (5 measured). Similar in general appearance, colour when alive and pigmentation when mounted to the alate viviparae. 1.738-2.025 mm long. Frons straight. Antennal segment III with 7-9 setae. Secondary sensoria scattered on antennal segment III and IV, and aligned on ventral face of segment $\mathrm{V}$, respectively 23-38(45), 14-20 and (6)1017. Marginal tubercles on the intermediate abdominal segments usually absent, and never more than one in total on both sides. Spinal sclerites smaller than those in alate viviparae, sometimes absent on anterior abdominal segments. Siphunculi cylindrical, shorter and less voluminous than those in alate viviparae. Abdominal segment 8 with 2 setae. Cauda almost triangular, with 10-16 setae. Omitted characteristics like those of the alate viviparous females. Metric features in Table 1.

\section{BIOLOGY}

Aphis cordubensis sp. n. is holocyclic and presumably monoecious, because the males are winged but there is no South American migrant species of Aphis. Abutilon megapotamicum is the only known hots plant for the species; it is also possible that it can host on plants of other Malvaceae genera, e.g. Callianthe pauciflora (A. St.-Hil.) Dorr., which is known in mountains of Cordoba province (FUENTES et al., 2012).

\section{DISTRIBUTION}

Aphis cordubensis sp. $\mathrm{n}$. is only known from its type locality but given the natural distribution and the use in gardening of its host plant, A. megapotamicum, it must be distributed in Argentina, Uruguay and Brazil.

\section{ETYMOLOGY}

The specific epithet is the Latin demonym of Córdoba, taken from the name of the Catholic Archdiocese of Córdoba, in feminine.

\section{TAXONOMIC DISCUSSION. DIAGNOSIS}

In South America, 79 species of the genus are known. Fifty-six species are native South American, and specimens of them [except of A. pseudopulchella Blanchard, 1944, living on Euphorbia portulacoides (Euphorbiaceae)] are preserved in the León University collection. The most relevant features of apterous viviparae to differentiate Aphis cordubensis sp. n. from those of these other species are the following: (1) marginal tubercles present on prothorax, abdominal segments 1 and 7; (2) usually marginal tubercles on inter- 
Table I - Aphis cordubensis sp. n., metric features. Body and its parts in millimetres, setae in microns. Lengths or proportions in parentheses are exceptional.

\begin{tabular}{|c|c|c|c|c|}
\hline & $\begin{array}{l}\text { apterous } \\
\text { viviparae }\end{array}$ & alate viviparae & oviparae & males \\
\hline body & $1.375-1.725$ & $\begin{array}{c}(1.613) 1.650- \\
2.425(2.600)\end{array}$ & $1.363-1.625$ & $1.738-2.025$ \\
\hline antenna & $0.775-0.975$ & $\begin{array}{c}(1.025) 1.113- \\
1.525(1.700) \\
\end{array}$ & $0.800-0.888$ & $1.250-1.425$ \\
\hline body / antenna & $1.58-1.91$ & $1.38-1.71$ & $1.54-1.97$ & $1.32-1.43$ \\
\hline ant.III & $0.18-0.21$ & $\begin{array}{c}(0.25) 0.27- \\
0.39(0.43) \\
\end{array}$ & $0.17-0.20$ & $0.31-0.35$ \\
\hline ant.III+IV & $0.25-030$ & /II & $0.27-0.30$ & $/ / /$ \\
\hline ant.IV & $0.11-0.14$ & $0.15-0.31$ & $0.10-0.12$ & $0.21-0.26$ \\
\hline ant.V & $0.12-0.15$ & $0.12-0.27$ & $0.12-0.15$ & $0.19-0.24$ \\
\hline ant.VI base & $0.08-0.11$ & $0.12-0.18$ & $0.10-0.12$ & $0.12-0.14$ \\
\hline ant.VI pr.ter. & $0.18-0.27$ & $0.27-0.37$ & $0.20-0.24$ & $0.30-0.35$ \\
\hline ant.III / $\Sigma$ ant.III to ant.VI & $0.23-0.29$ & $0.25-0.31$ & $0.22-0.25$ & $0.2-0.3$ \\
\hline ant.III+IV / $\Sigma$ ant.III to ant.VI & $0.35-0.41$ & //I & $0.36-0.41$ & I/I \\
\hline ant.III / siph. & $1.2-1.5$ & $1.4-2.1$ & $1.4-1.8$ & $2.4-3.1$ \\
\hline ant.III+IV / siph. & $1.9-2.2$ & $/ / /$ & $2.2-2.6$ & III \\
\hline ant.VI pr.ter. / ant.VI base & $1.7-2.7$ & $2.0-2.7$ & $1.9-1.9$ & $2.3-2.9$ \\
\hline ant.III / ult.rostr. & $1.3-1.7$ & $1.9-2.6$ & $1.4-1.7$ & $2.3-2.6$ \\
\hline ant.III+IV / ult.rostr. & $2.2-2.7$ & $/ / /$ & $2.3-2.4$ & //I \\
\hline ant.VI pr.ter. / ant.III & $0.9-1.5$ & $0.8-1.1$ & $1.1-1.3$ & $0.9-1.1$ \\
\hline ant.VI pr.ter. / ant.III+IV & $0.6-0.9$ & $/ / /$ & $0.7-0.8$ & $/ / /$ \\
\hline ant.VI per.ter. / ult.rostr. & $1.4-2.2$ & $1.9-2.5$ & $1.6-1.6$ & $2.3-2.6$ \\
\hline ult.rostr. & $0.11-0.14$ & $0.13-0.17$ & $0.12-0.13$ & $0.13-0.14$ \\
\hline ult.rostr / bØ ult.rostr. & $1.8-2.4$ & $2.6-3.2$ & $1.8-2.7$ & $2.2-2.7$ \\
\hline ult.rostr. / ant.VI base & $1.0-1.6$ & $0.9-1.2$ & $1.0-1.3$ & $0.9-1.1$ \\
\hline ult.rostr. / hind tars. 2 & $1.1-1.3$ & $1.1-1.3$ & $1.2-1.3$ & $1.2-1.3$ \\
\hline hind tibia & $0.57-0.75$ & $\begin{array}{c}0.85- \\
1.25(1.43) \\
\end{array}$ & $0.52-0.61$ & 0.98 \\
\hline body / hind tibia. & $\begin{array}{c}(2.05) 2.30- \\
2.63 \\
\end{array}$ & $1.76-2.14$ & $2.22-3.10$ & $1.93-2.10$ \\
\hline hind tars. 2 & $0.10-0.11$ & $0.11-0.13$ & $0.09-0.10$ & $0.10-0.12$ \\
\hline siphunculus & $0.13-0.17$ & $\begin{array}{c}0.12- \\
0.23(0.31) \\
\end{array}$ & $0.11-0.13$ & $0.11-0.14$ \\
\hline cauda & $0.15-0.19$ & $0.13-0.23$ & $0.13-0.17$ & $0.13-0.15$ \\
\hline siphunculus / body & $0.08-0.11$ & $0.07-0.12$ & $0.07-0.10$ & $0.06-0.08$ \\
\hline siphunculus / mØ siphunculus & $2.6-3.3$ & $(2.5) 3.0-5.0$ & $1.9-2.8$ & $3.0-4.0$ \\
\hline siphunculus mØ / h.tib. mØ & $0.9-1.5$ & $1.1-1.7$ & $0.4-0.6$ & $1.0-1.2$ \\
\hline siphunculus / cauda & $0.7-0.9$ & $0.9-1.3$ & $0.7-0.9$ & $0.8-1.1$ \\
\hline
\end{tabular}




\begin{tabular}{|c|c|c|c|c|}
\hline cauda / bØ cauda & $1.2-1.6$ & $1.1-1.5$ & $1.0-1.4$ & $1.1-1.3$ \\
\hline st. ant.III & $25-38$ & $23-38$ & $25-38$ & $20-30$ \\
\hline st. ant.III / s $\emptyset$ ant.III & $1.5-2.5$ & $1.2-2.3$ & $1.4-2.3$ & $1.1-1.4$ \\
\hline st. dorsal head & $40-48$ & (28)35-63 & $30-48$ & $30-40$ \\
\hline st. dorsal head / sØ ant.III & $2.4-3.2$ & $(1.2) 2.0-4.2$ & $2.0-3.2$ & $1.3-2.0$ \\
\hline st. hind trochanter & $40-63$ & $35-58$ & $38-63$ & $35-48$ \\
\hline st. hind trochanter / troch-fem. $\varnothing$ & $1.1-1.6$ & $0.9-1.6$ & $0.8-1.3$ & $0.8-1.1$ \\
\hline st. dors. hind femur & $38-55$ & $35-60$ & $38-53$ & $30-55$ \\
\hline st.. dors. hind femur / s $\emptyset$ ant.III & $2.3-3.7$ & $1.6-3.8$ & $2.3-3.5$ & $1.4-2.8$ \\
\hline st. ventr.hind femur & $43-53$ & $35-60$ & $38-50$ & $28-38$ \\
\hline st.. ventr. femur / sØ ant.III & $2.4-3.6$ & $1.6-4.4$ & $2.1-3.2$ & $1.3-1.9$ \\
\hline st. middle-dors. h.tib. & $35-60$ & $38-55(63)$ & $43-63$ & $38-50$ \\
\hline st. middle-dors. h.tib. / mØ h.tib. & $0.9-2.0$ & $1.0-1.7$ & $0.4-0.8$ & $1.1-1.5$ \\
\hline st. abd.2-4 & $38-55$ & $35-58$ & $30-45$ & $25-50$ \\
\hline st. abd.2 / s $\emptyset$ ant.III & $2.1-3.5$ & $1.9-3.4$ & $1.7-3.0$ & $1.4-2.5$ \\
\hline st. abd.8 & $48-73$ & $45-70$ & $48-63$ & 40.53 \\
\hline st. abd.8 / sØ ant.III & $2.9-4.5$ & $2.2-3.8$ & $2.7-4.2$ & $2.2-2.5$ \\
\hline st. genital plate & $38-50$ & $30-60$ & $35-50$ & /// \\
\hline
\end{tabular}

Abbreviations: abd. $=$ abdominal segment; ant. $=$ antennal segment $(\mathrm{s}) ; \mathrm{b} \emptyset=$ width at base dors. $=$ dorsal; h.tib. $=$ hind tibia; $\mathrm{m} \emptyset=$ width at middle length; pr.ter. = processus terminalis; siph. = siphunculus; st. = longest seta; $\varnothing \varnothing=$ subarticular width; tars. 2 = second tarsal segment; troch-fem. $\varnothing=$ hind trochantero-femoral suture width; ult.rostr. = ultimate rostral segment; ventr. $=$ ventral.

mediate abdominal segments, 1 or 2 on each side of abdominal segments 2-4; (3) clypeus no swollen; (4) dorsum of thorax and abdomen widely membranous, abdominal segment 8 with or without sclerotized transverse band; (5) tarsal formula 3.3.2; (6) antennae without secondary sensoria, five- or six-segmented; (7) processus terminalis long, 1.7-2.7 times antennal segment VI base, and 1.4-2.2 times ultimate rostral segment; (8) ultimate rostral segment longer than second segment of hind tarsi, 1.1-1.3 times; (8) siphunculi homogeneously dark, $0.08-0.11$ times body length and 0.7-0.9 times cauda; (10) cauda long and broad fingershaped, dark and with 10-18 setae; and (11) fine, pointed and very long setae, those largest on antennal segment III, head, femora and abdominal segments always more or much longer than the subarticular width of antennal segment III (see Table I), longest dorsal and setae on the middle of hind tibiae usually longer than the width of the segment at the middle length, and internal setae on hind trochanters longer than trochantero-femoral suture.

The number of species of the genus Aphis worldwide known is very big, more than 500, so the taxonomic discussion of the new species of the genus - that is, the presentation of the differences of the species in relation to other species of the genus - is habitually limited to species that share plant-host, genus or family. Fifteen species of Aphis are worldwide known hosted on species of 46 genera of Malvaceae (BLACKMAN and EASTOP (2021): A. althaeae (Nevsky, 1929), A. aurantii (Boyer de Fonscolombe, 1841), A. citricidus (Kirkaldy, 1907), A. coreopsidis (Thomas, 1878), A. craccivora Kaltenbach, 1854, A. eugeniae van der Goot, 1917, A. fabae Scopoli, 1763, A. frangulae Kaltenbach, 1845, A. gossypii Glover, 1877, A. nasturtii Kaltenbach, 1843, A. odinae (van der Goot, 1917), A. solanella Theobald, 1914, A. spiraecola Patch, 1914, A. umbrella (Börner, 1950 ) and $A$. sp. aff. craccivora (in press). The apterous viviparae of these species can be differentiated from those of the new species using the following summarized key, which is a simplification of the "Key to apterae on Hibiscus" and the "Key to apterae of polyphagous aphids" by BLACKMAN and EASTOP (2021); modifications or addition on these keys are enclosed in brackets. The species that have been cited in South America - although no necessarily from Argentina or Chile - are indicated by asterisks. 
1. Siphunculi pale, or only dusky near apices A. althaeae, A. nasturtii*, A. umbrella

- Siphunculi dark 2

2. Head, antennal segments I, II and basal part of III very pale, contrasting with dark rest of antenna. Siphunculi noticeably paler than cauda A. coreopsidis*

- Head and antennal segments differently pigmented Siphunculi usually less than 0.24 times body length. [Siphunculi as dark as cauda] 3

3. Dorsal abdomen [usually] with an extensive solid black sclerite centred on abdominal tergites 4 and 5 [if reduced or even absent, then clypeus moderately swollen].........A. craccivora*, A. sp. aff craccivora (in press)*

- Dorsal abdomen with or without dark markings, but without an extensive solid black sclerite [and with not swollen clypeus]

4. Stridulatory apparatus present A. aurantiae*, A. citricidus*, A. odinae

- Stridulatory apparatus not present 5

5. Cauda pale, dusky or dark, bearing 4-7(-8) hairs. Longest hind femoral hairs only 0.4-0.7 times the trochantero-femoral suture

A. gossypii* [plus A. frangulae]

- Cauda always dark like SIPH, and bearing 7-24 hairs. Longest hind femoral hairs usually more than 0.7 times the trochantero-femoral suture 6

6. Siphunculi usually more than 0.9 times cauda, if $0.7-0.9$ then antennal segment III 1.2-1.9 times cauda and dorsal abdomen usually has some dark markings anterior to siphunculi

A. asclepiadis*, A. fabae A. solanella*, A. spiraecola* [plus A. eugeniae]

- Siphunculi 0.9 times cauda at most, and antennal segment III 1.0-1.2 times cauda if six-segment antennae or antennal segments III+IV 1,5-1.8 times cauda if five-segmented antennae

A. cordubensis sp. n.

\section{PHYTOSANITARY COMMENT}

The host plant of the new species - Abutilon megapotamicum, trailing abutilon - has gardening interest. It is advisable to monitor the plants of the genus Abutilon, and even of other genera of Malvaceae, that are commercialized or that are reproduced by cuttings, to avoid the dispersal of Aphis cordubensis.

\section{REFERENCES}

BLACKMAN R.L., EASTOP V.F., 2021 - Aphids on the World's Plants. An online identification and information guide. Available from http://www.aphidsonworldplants.info/ Accessed June 2021.

Fuentes E., Martinat J.E., CARbone L.M., 2012 Reconocimiento de diásporas de Malveae (Malvaceae) en muestras de suelos de zonas serranas (Sierras Chicas, Córdoba, Argentina) afectadas por incendios. - Rodriguesia, 63(3): 501-512.

LÓPEZ CIRUElos S.I., ORTEGO J., MIER DURANTE M.P., NIETO NAFRÍA J.M., 2017 - A new species of Aphis Linnaeus, 1758 (Hemiptera, Aphididae) collected on Gymnophyton Clos. (Apiaceae) in Argentina. Graellsia, 73(1), e055: 1-9.

NIETO NAFRÍA J.M., BROWN P.A., LÓPEZ CIRUELOS S.I., ORTEGO J., 2019 - A new species of Aphis (Hemiptera, Aphididae) living on Tropaeolum species (Tropaeolaceae) from Chile and Argentina. Redia, 102: 35-40. http://dx.doi.org/10.19263/ REDIA-102.19.05 